\title{
Hormonal contraception and risk of endometrial cancer: a systematic review
}

\author{
Alfred O Mueck, Harald Seeger and Thomas Rabe
}

Department of Endocrinology and Menopause, Centre for Women's Health BW, University Women's Hospital, Calwer Strasse 7, D-72076 Tuebingen, Germany

(Correspondence should be addressed to A O Mueck; Email: alfred.mueck@med.uni-tuebingen.de)

\begin{abstract}
More than 15 case-control studies and at least four large cohort studies demonstrated a decrease in the risk of endometrial cancer of about $50 \%$ for ever use of combined oral contraceptives (COCs). In most of these studies, this protective effect persisted for more than 10-15-20 years after cessation of the COC. An increasing protective effect with longer duration of COC use has been found in most studies. The beneficial effect was independent of the composition of COC, i.e. dosage and type of progestogen, combined with ethinyl estradiol 30-50 $\mu \mathrm{g} / \mathrm{day}$. COCs with higher progestogen potency seem to be somewhat more effective. Nonhormonal uterine devices have also been found to be strongly protective; however, data on oral or injectable progestogen-only preparations (POPs) including the levonorgestrel-releasing intrauterine system (LNG-IUS) are still rare, but also suggest similar protective action. COCs, POPs, as well as LNG-IUS can effectively reduce endometrial hyperplasia but should only be used in exceptional cases in patients with or after endometrial cancer. In contrast to nonhormonal IUS, systemic side effects cannot be excluded with LNG-IUS, but they are certainly rare, as the main effect has decreased the endometrial estrogen response because of the high endometrial tissue levels of LNG.
\end{abstract}

Endocrine-Related Cancer (2010) 17 R263-R271

\section{Introduction}

Two different clinicopathological subtypes of endometrial cancer are recognized: estrogen-related type 1 (endometroid), comprising $70-80 \%$ of newly diagnosed cancer, and nonestrogen-related type 2 (nonendometroid such as papillary serous and clear cell).

The biological basis of type 1 is that estrogen stimulates endometrial cell division, whereas progestogens block this effect. As a result of progestogen action, cell proliferation ceases, despite continuous exposure to estrogen levels (as in the luteal phase). Progestogens protect from estrogen-induced hyperplasia and changes in proliferative status. They induce glandular epithelial secretory activity and decidual transformation of stromal fibroblasts; these terminaldifferentiated cells can no longer proliferate and are shed in withdrawal bleeding (if implantation does not occur), with important differences dependent on the pharmacology of the progestogens used (type, dosage, pharmacokinetics, etc).

However, many more changes in histological features occur during hormonal contraception treatment, such as different proliferatory, secretory, and atrophic (like) patterns, changes in glandto-stroma ratio, stromal factors (e.g. very potent growth factors), architectural structures (e.g. cribiform and/or papillary patterns), glandular cellularity, cytoplasmic changes, mitotic activity, (tumor-)angiogenesis, and increase or decrease in cytologic atypia; the latter are powerful markers and predictors for progestogenic potency.

Most, if not all, of these effects, which are still a topic of important ongoing research, suggest that hormonal contraceptives can reduce the risk of endometrial cancer. To demonstrate a causal relationship in clinical studies would require randomized placebo-controlled interventional studies, which are not ethical in the field of contraception. Thus, the aim of this systematic review was to search for observational studies with a focus on case-control and cohort studies and to summarize the results, especially those of the most important (large) studies. To our knowledge, the last systematic review on this topic was published more than 15 years ago. 
Although observational studies can only evaluate associations, not causality between cancer risk and hormonal use in this case, it is very important for daily practice to know if we have to expect an increase or decrease in the risk, and how great the evidence is, which points in one or the other direction.

\section{Method of systematic review}

The literature review included a search in MEDLINE from the start of this database in January 1969. This was the prime source for this report. In addition, we searched the PubMed and EMBASE databases for studies after 1980. Key words were ('contraceptives' or 'exogenous hormones') and ('endometrial cancer' or 'neoplasm') and ('case-control study' or 'cohort study'). The search was primarily limited to English language articles. To be considered for inclusion, publications had to be original articles.

We included all cohort and case-control studies up to December 2009. We retrieved and assessed potentially relevant articles, and checked the reference lists of all papers of interest to identify additional relevant publications. At least, two of the authors selected and extracted the studies followed by double checking both literature searches and data extraction.

Studies were only included if they considered information on contraceptives separately from hormone replacement therapy (HRT) or other hormonal therapies. We did not consider abstracts and case reports regarding studies with combined oral contraceptives (COCs), but due to the lack of data, we also searched for case reports about the risk with progestogen-only preparations (POPs) and levonorgestrel-releasing intrauterine system (LNGIUS), which were published in well-known journals. Accordingly, because of the lack of data, we searched for progestogen-only contraception (especially including LNG-IUS) with the keyword 'endometrial hyperplasia'.

The present review is of qualitative and empirical nature, and no statistical analysis was used to compare the various studies. The prime objective was to evaluate whether there is a strong association between increased or decreased risk of endometrial cancer and contraceptive use. We did not check for adjustments in the various studies, although it is well known that factors such as age, family history, parity, smoking, genetics, and body mass index (BMI) have been shown as basic risk factors for endometrial cancer. Most studies using hormonal contraceptives have been adjusted for the most important factors that increase endometrial cancer risk such as age, BMI, family history, and smoking. However, the modulating effect of these factors on the risk profile during use of hormonal contraception has only been investigated in a few studies with small subgroup numbers. All in all, it seems that these factors have only a minor influence, if at all, on the protective effect of hormonal contraceptives.

\section{Early case-control and cohort studies}

The first relevant systematic review using the criteria of the US Preventive Services Task Force and evaluating the association between COCs and endometrial cancer was published in 1995 (Grimes \& Economy 1995), assessing 13 case-control studies (Horwitz \& Feinstein 1979, Kaufman et al. 1980, Weiss \& Sayvetz 1980, Hulka et al. 1982, Kelsey et al. 1982, Henderson et al. 1983, LaVecchia et al. 1986, Pettersson et al. 1986, CASH 1987, Koumantaki et al. 1989, WHO Collaborative Study 1991a,b, Brinton \& Hoover 1993, Jick et al. 1993, Maxwell et al. 2006) and 3 cohort studies (Ramcharan et al. 1981, Trapido 1983, Beral et al. 1988; Fig. 1).

The first report, published in 1979 , was a casecontrol study ( $n=268 / 268$, Yale Registry, USA) and has failed to support an association between COC use and endometrial cancer (odds ratio (OR) 0.95). However, all the other early case-control studies found a protective effect ranging from OR 0.1 to 0.6 , with most clustering around 0.5 . In several reports, the protection was significant (Kaufman et al. 1980, CASH 1987, Brinton \& Hoover 1993, Jick et al. 1993) including the largest case-control study and the Cancer and Steroid Hormone Study of the Centers for Disease Control (CASH) (CASH 1987).

Only one study, a cohort study in Eastern Massachusetts, found a modest, nonsignificant increase in risk (Trapido 1983), but included highdose sequential preparations $(100 \mu$ g ethinyl estradiol (EE)) combined with low-dose, short sequential progestin, which has been off the market for over 20 years. Two of the three cohort studies reported a significant protective effect. These included the Walnut Creek Contraceptive Drug Study from California (Ramcharan et al. 1981) and the Study from the Royal College of General Practitioners (Beral et al. 1988). This UK study is the most important cohort study, evaluating the 47000 women 1988 report, that found an $80 \%$ reduction in risk (relative risk (RR) 0.2 ; $95 \%$ CI $0.0-0.7$ ). 


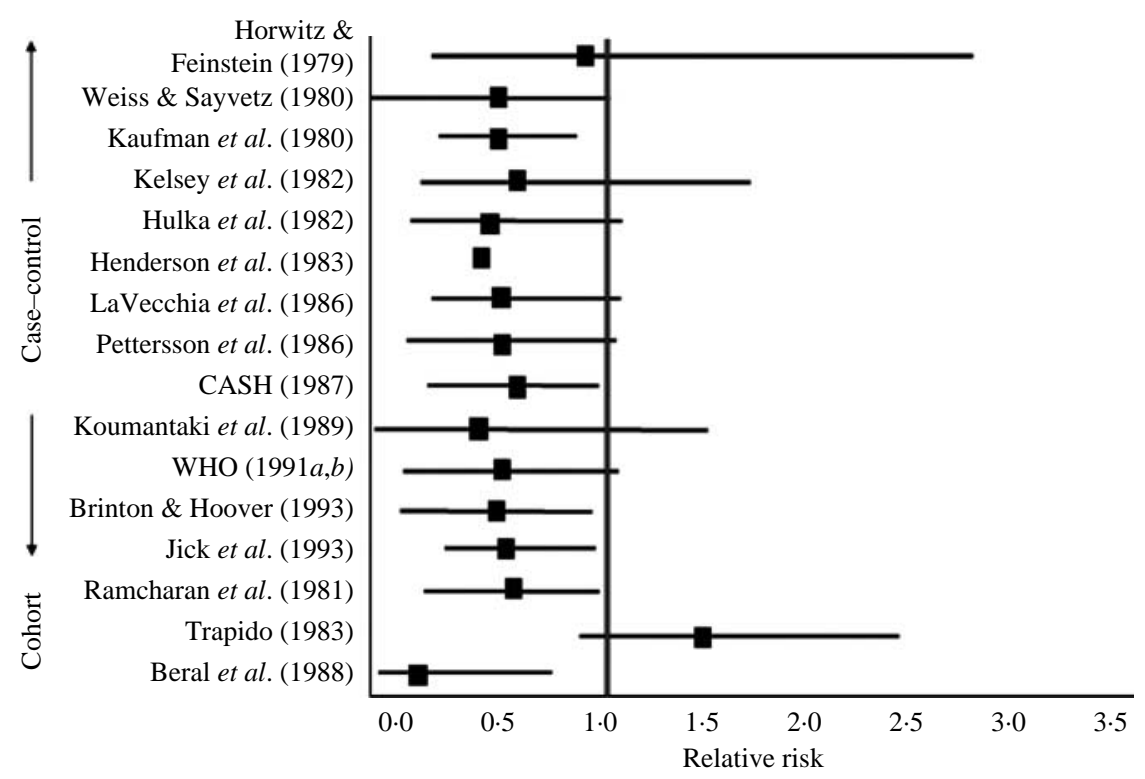

Figure 1 Risk of endometrial cancer associated with ever use of combined oral contraceptives modified from American Journal of Obstetrics and Gynecology, Grimes \& Economy, Primary prevention of gynecologic cancers, Copyright (1995), with permission from Elsevier.

\section{Important studies on the risk of using COC}

Only a few more relevant studies have been published up to now, which also investigated the follow-up of earlier large studies and risk factors, which could possibly modulate the effect of hormonal contraceptive use. Table 1 summarizes the most important studies in chronological sequence of publications.

The most important study using incident cohort data in large patient samples has been the Royal College Study (Beral et al. 1988), and the recently published data followed 45950 women for a mean of 24 years (Hannaford et al. 2007). The data came from 6-monthly reports from the women's general practitioners until 1996, and from linkage of 35050 women who were still in the study in the mid-1970s to National Health Service central registries. The main dataset contained about 339000 woman-years of observation for never users and 744000 woman-years for ever users. Most of the pills were COCs, only 3\% were progestin-only pills (POP).

Compared with never users, ever users had statistically significant lower rates of cancers of the uterine body, calculated in the main dataset with RR 0.58 (95\% CI 0.42-0.79), standardized rate per 100000 woman-years 11.30/19.53 (adjusted for age, parity, smoking, and social status). The risk of duration of OC use was also assessed (general practitioner dataset). Even with small numbers, the trend for longer use was statistically significant. With regard to recent use, only $<5$ years after stopping using oral contraception reached significance. As only 566 women exclusively used COC containing more than $50 \mu \mathrm{g}$ EE, this study cannot answer the question of how much the risk is dependent on the hormonal potencies of the COC.

This question was specifically investigated in the WHO Collaborative Study (1991a,b), which classified COC according to the dosage of EE and potency/dosage of progestin. High-dose EE/low progestin did not alter the risk (OR 1.10; 95\% CI 0.13-9.96), in contrast (not significant) to low-dose EE/high progestin (OR 0.0; 95\% CI 0-1.08) and low EE/low progestin (OR 0.59; 95\% CI 0.26-1.30). High-dose versus low-dose progestin significantly decreased the risk (OR 0.21 ; 95\% CI 0.05-0.84).

The multicenter, population-based case-control study with the longest duration up to now is the still ongoing CASH study, with enrollment between 1980 and 1982 at eight US regional cancer registries participating in the Surveillance Epidemiology Program of the National Cancer Institute. The first larger evaluation in 1987 (CASH 1987) included 433 cases and 3191 controls, limited to women aged $20-54$ years. Women who had used OCs for at least 1 year had an age-adjusted risk of 0.6 (95\% CI 0.3-0.9). This protective effect persisted for at least 15 years after cessation of COC use. The protective effect was independent of the type of histology.

The latest evaluation of CASH (Maxwell et al. 2006) also focused on the hormonal potencies, including 434 endometrial cancer cases and 2557 controls. 
Table 1 Risk of endometrial cancer during oral contraception (relevant studies listed in chronological sequence)

\begin{tabular}{|c|c|c|c|c|c|c|c|}
\hline \multirow[b]{2}{*}{ First author } & \multirow[b]{2}{*}{ Country } & \multirow[b]{2}{*}{ Cases } & \multirow[b]{2}{*}{ Controls } & \multirow[b]{2}{*}{$\begin{array}{l}\text { Age } \\
\text { (years) }\end{array}$} & \multicolumn{2}{|c|}{ Risk influenced by } & \multirow[b]{2}{*}{$\begin{array}{l}\text { RR } \\
\text { (ever users) }\end{array}$} \\
\hline & & & & & $\begin{array}{l}\text { Investigated } \\
\text { factors }\end{array}$ & OC-duration & \\
\hline Horwitz (1979) & USA & 104 & 87 & 50 & & n.a. & 0.94 \\
\hline Weiss (1980) & USA & 110 & 249 & $35-54$ & $b, d$ & n.a. & 0.5 \\
\hline Kaufmann (1980) & USA & 152 & 516 & $>60$ & $c, d$ & Yes & 0.5 \\
\hline Ramcharan (1981) & USA & 58 & 16638 (cohort) & $>65$ & & n.a & 0.6 \\
\hline Kelsey (1982) & USA & 37 & 342 & $45-74$ & & Yes & 0.6 \\
\hline Hulka (1982) & USA & 79 & 203 & n.a. & $\mathrm{a}$ & Yes & $0.3-0.6$ \\
\hline Henderson (1983) & USA & 110 & 110 & $<45$ & $b, c, d, f$ & Yes & 0.75 \\
\hline Trapido (1983) & USA & 98 & 97300 (cohort) & $<58$ & & n.a. & 1.4 \\
\hline LaVecchia (1986) & Italy & 170 & 1282 & $<60$ & & n.a. & 0.56 \\
\hline Pettersson (1986) & Sweden & 362 & 367 & $<60$ & $c$ & n.a. & 0.4 \\
\hline Ory (CASH) (1987) & USA & 433 & 3191 & $25-54$ & $a, b, c, d, f, g$ & Yes & 0.6 \\
\hline Beral (1988) & UK & & 47000 (cohort) & n.a. & & n.a. & 0.2 \\
\hline Koumantaki (1989) & Greece & 83 & 164 & $40-79$ & & Yes & 0.65 \\
\hline Levi (1991) & Switzerland & 122 & 309 & $\leq 75$ & $a, c, e, f$ & Yes & 0.5 \\
\hline Stanford (1993) & USA & 405 & 297 & n.a. & $a, d, e, f$ & Yes & 0.4 \\
\hline WHO Collaborative $(1991 a, b)$ & USA & 220 & 1537 & $>65$ & $b, c$ & n.a. & $\begin{array}{l}1.10^{\mathrm{a}} \\
0.15^{\mathrm{b}} \\
0.59^{\mathrm{c}}\end{array}$ \\
\hline Weiderpass (1999) & Sweden & 709 & 3368 & $50-74$ & $a-g$ & Yes & 0.5 \\
\hline Heinemann (2003) & Germany & 485 & 1570 & $32-65$ & $a-g$ & Yes & 0.36 \\
\hline Maxwell (CASH) (2006) & USA & 434 & 2557 & $25-54$ & $b, e, f$ & Yes & $\begin{array}{l}0.21^{d} \\
0.39^{e}\end{array}$ \\
\hline Vessey (Oxford-FPA) (2006) & UK & 77 & 17032 (cohort) & $\begin{array}{l}25-39 \\
\quad \text { (recrution) }\end{array}$ & $a, b, c$ & Yes & 0.1 \\
\hline Hannaford (2007) & UK & 156 & 47173 (cohort) & & & Yes & 0.58 \\
\hline
\end{tabular}

n.a., no answer; a, duration; b, composition; c, persistence of protection; d, hormone therapy after OC; e, parity; f, weight; g, histology; n.a., not applicable; CASH, Cancer and Steroid Hormone Study.

${ }^{\mathrm{a}}$ High dose estrogen/low dose progestin.

${ }^{\mathrm{b}} \mathrm{High}$ dose estrogen/high dose progestin.

'Low dose estrogen/low dose progestin.

dHigh potency progestin.

e Low potency progestin.

Compared with nonusers, high-progestin COC as well as low-progestin COC significantly decreased the risk (OR 0.21 ; 95\% CI $0.10-0.43$ and OR 0.39 ; 95\% CI $0.25-0.60$ respectively), but only high-progestin COCs were protective in women with a BMI > 22 (OR 0.31; 95\% CI 0.11-0.92).

Likewise, in a large population-based Swedish case-control study $(n=709 / 3368)$ (Weiderpass et al. 1999), high-, medium-, and low-dose progestin COC reduced the risk, although it was only significant with high and medium dosages (adjusted OR 0.7; 95\% CI 0.5-0.9). This protective effect was similar for all degrees of tumor differentiation and invasiveness. As only postmenopausal women aged 50-74 years were investigated, subsequent use of HRT was also assessed, and was not found to modify the protective effect of the $\mathrm{COC}$ used at a younger age. The reduction in risk was noticeable after 3 years of use (OR $0.5 ; 95 \%$ CI $0.3-0.7)$, and increased with duration of intake, reaching $80 \%$ lower risk after 10 years of use
(OR 0.2; 95\% CI 0.1-0.4), and as in the CASH study, the protective effect remained for at least 15-20 years after cessation of COC.

Almost similar results have been found in a German population-based case-control study ( $n=485 / 1570$; Heinemann et al. 2003) with the reduction in risk comparable for all COCs used (adjusted OR 0.36; 95\% CI 0.28-0.45, ever versus never use) comparable to low-dose COC (OR 0.30; 95\% CI 0.12-0.74), and a protective effect starting within 5 years (OR $0.63 ; 95 \%$ CI 0.47-0.86), increasing with duration of use, reaching $75 \%$ lower risk after 10 years (OR 0.25 ; $95 \%$ CI $0.18-0.34$ ), and persisting for more then 10 years after stopping pill use.

Similar trends were also observed in a large recent Chinese case-control study (Tao et al. 2006; $n=1.204 / 1.212$ ). The risk for ever users of COC was decreased (OR 0.75 ; 95\% CI 0.60-0.93), the protective effect increased with duration of use (5 years or more: OR $0.50 ; 95 \%$ CI $0.30-0.85$ ) and remained for 25 years 
after cessation of use (OR 0.57 ; 95\% CI $0.42-0.78$ ). Similar results have been found in further case-control studies, which are listed in Table 1 (WHO 1988, Levi et al. 1991, Stanford et al. 1993).

The 2006 update on the Oxford family planning association cohort study evaluating 17032 women has been published recently (77 cases), with a more than $50 \%$ reduction in ever users ( $R R$ for $97+$ months 0.1 (95\% CI 0.0-0.4)) and a protective effect lasting for more than 20 years after cessation of OCs. In this analysis (Vessey \& Painter 2006), the data for the cancers of the cervix, uterine body, and ovary were also combined, resulting in an age-adjusted RR 0.7 (95\% CI 0.5-0.8).

\section{Time dependency of risk reduction}

Increasing protective effects with duration of $\mathrm{COC}$ use have been found in most studies that have investigated this issue (Table 2). A systematic meta-analysis (Schlesselman 1997) including ten case-control studies (Kaufman et al. 1980, Weiss \& Sayvetz 1980, Hulka et al. 1982, Kelsey et al. 1982, Henderson et al. 1983, LaVecchia et al. 1986, Pettersson et al. 1986, CASH 1987, Levi et al. 1991, Stanford et al. 1993) and the cohort study of the Royal College of General Practitioners (Beral et al. 1988) calculated a significant reduction of risk with RR $0.44,0.33$, and 0.28 after 4 , 8 , and 12 years of COC use respectively based on 33 time-dependent estimates of RR, adjusted for age, adiposity, parity, and use of estrogen replacement therapy. The trend of decreasing risk with increasing duration of use of COC was highly significant $(P<0.0001$, one sided $)$.

In this meta-analysis, the adjusted RRs by recency of use of COC were also calculated, based on 19 estimates of RRs. After stopping COC, the decrease in risk persisted for 20 years after discontinuation, and the trend for decrease in risk reduction was significant $(P=0.011$, one sided $)$, but still remained about $50 \%$ (RR $0.33,0.41$, and 0.51 for 5,10 , and 20 years after pill cessation respectively). Of interest, seems the fact that the residual protective effect from prior COC use continues throughout the menopause, at a time when the risk of endometrial cancer is greatest.

\section{Risk using oral and injectable progestin-only preparations}

All the studies listed in Fig. 1 investigated the effect of COC; progestin-only preparation (POP) users were only separately tabulated in the CASH and WHO studies, with very small numbers (WHO 1991a,b,
Table 2 Data on relative risk (RR) of invasive endometrial cancer in relation to duration of use of combined oral contraceptives

\begin{tabular}{|c|c|c|c|c|}
\hline First author & Duration & Cases & Controls & $\mathbf{R R}$ \\
\hline \multirow{3}{*}{$\begin{array}{l}\text { Kaufman } \\
(1980)\end{array}$} & $<1$ year & 141 & 425 & 0.8 \\
\hline & $1-2$ years & 142 & 443 & 0.5 \\
\hline & $3+$ years & 141 & 454 & 0.3 \\
\hline Weiss (1980) & $\geq 1$ year & 110 & 249 & 0.5 \\
\hline \multirow[t]{2}{*}{ Kelsey (1982) } & $\leq 2.5$ years & 35 & 298 & 0.9 \\
\hline & $>2.5$ years & 33 & 300 & 0.5 \\
\hline \multirow[t]{2}{*}{ Hulka (1982) } & $<5$ years & 77 & 186 & 0.6 \\
\hline & $>5$ years & 76 & 189 & 0.3 \\
\hline \multirow{4}{*}{$\begin{array}{c}\text { Henderson } \\
\text { (1983) }\end{array}$} & $<2$ years & 90 & 72 & 0.8 \\
\hline & $2-3$ years & 79 & 61 & 0.8 \\
\hline & $4-5$ years & 71 & 59 & 0.3 \\
\hline & $6+$ years & 71 & 68 & 0.1 \\
\hline \multirow{2}{*}{$\begin{array}{l}\text { LaVecchia } \\
\text { (1986) }\end{array}$} & $\leq 2$ years & 166 & 1213 & 0.2 \\
\hline & $>2$ years & 167 & 1173 & 0.4 \\
\hline \multirow{3}{*}{$\begin{array}{c}\text { Petterson } \\
\text { (1986) }\end{array}$} & $<1$ year & 101 & 97 & 0.8 \\
\hline & $1-2$ years & 97 & 97 & 0.2 \\
\hline & $3+$ years & 99 & 101 & 0.3 \\
\hline \multirow[t]{6}{*}{ CASH (1987) } & $3-6$ months & 274 & 1333 & 0.9 \\
\hline & $7-11$ months & 263 & 1227 & 1.3 \\
\hline & $12-13$ months & 270 & 1413 & 0.7 \\
\hline & 24-71 months & 276 & 1723 & 0.4 \\
\hline & $\begin{array}{l}\text { 72-119 } \\
\text { months }\end{array}$ & 262 & 1464 & 0.4 \\
\hline & $120+$ months & 265 & 1388 & 0.4 \\
\hline \multirow[t]{2}{*}{ Beral (1988) } & $<5$ years & 17 & 13.338 & 0.2 \\
\hline & $5-9$ years & 17 & 11.412 & 0.2 \\
\hline \multirow[t]{3}{*}{ Levi (1991) } & $<2$ years & 114 & 246 & 1.0 \\
\hline & $2-5$ years & 108 & 245 & 0.5 \\
\hline & $>5$ years & 110 & 272 & 0.3 \\
\hline \multirow{5}{*}{$\begin{array}{r}\text { Stanford } \\
(1993)\end{array}$} & $<1$ year & 348 & 208 & 0.7 \\
\hline & $1-2$ years & 337 & 220 & 0.3 \\
\hline & $3-4$ years & 333 & 203 & 0.3 \\
\hline & $5-9$ years & 335 & 202 & 0.7 \\
\hline & $10+$ years & 328 & 206 & 0.2 \\
\hline \multirow{4}{*}{$\begin{array}{l}\text { Weiderpass } \\
\text { (1999) }\end{array}$} & $<1$ year & 63 & 245 & 1.2 \\
\hline & $1-4$ years & 47 & 292 & 0.7 \\
\hline & 5-9 years & 20 & 190 & 0.6 \\
\hline & $10+$ years & 6 & 212 & 0.2 \\
\hline \multirow{3}{*}{$\begin{array}{l}\text { Heinemann } \\
\text { (2003) }\end{array}$} & $<6$ years & 75 & 257 & 0.6 \\
\hline & $6-10$ years & 27 & 199 & 0.3 \\
\hline & $10+$ years & 62 & 521 & 0.3 \\
\hline \multirow[t]{3}{*}{ Vessey (2006) } & $<49$ months & 12 & 50 & 0.6 \\
\hline & 49-96 months & 11 & 50 & 0.4 \\
\hline & $77+$ months & 4 & $\begin{array}{c}50 \text { (cohort } \\
17.032 \text { ) }\end{array}$ & 0.1 \\
\hline
\end{tabular}

Maxwell et al. 2006). In CASH, only one case and six controls had used POPs exclusively, resulting in a crude OR of 0.6 (95\% CI 0.1-5.0). The WHO Collaborative Study of Neoplasia and Steroid Contraception, a hospital-based case-control study comparing 220 cases from 7 countries with 1537 age-matched controls, found no cases and only 2 controls who had exclusively used oral POPs. 
Newer studies also included only small patient samples. As only 3\% were POP users in the large cohort study from the Royal College, risks have not been calculated (Hannaford et al. 2007). In a large Swedish case-control study (Weiderpass et al. 1999) from 707 cases $/ 3368$ controls, only $7 / 61$ used the mini pill (OR $0.4 ; 95 \%$ CI $0.2-1.4$ ) and $0 / 14$ depotmedroxyprogesterone acetate (DMPA).

Up to now, we have very little knowledge about the protective effect of using POPs. Therefore, inferences about POPs must be made from knowledge about COCs, other risk factors, and biological mechanisms.

\section{Risk using nonhormonal and hormonal intrauterine devices}

A meta-analysis has been published recently (Beining et al. 2008), based on a comprehensive search of literature published up to 2007 , to examine the association on ever use of different nonhormonal intrauterine devices (IUDs) and endometrial cancer. By pooling ten studies, a strong protective effect from IUDs was observed (pooled adjusted OR 0.54; $95 \%$ CI 0.47-0.63). With the exception of one small Chinese study (Shu et al. 1991; OR 1.10; 95\% CI $0.50-2.50$ ), the protection was seen in all the studies (seven significant), increased with the duration of use, and was still to be observed 5 years after cessation of use (OR 0.91; 95\% CI 0.86-0.95). Only three studies reported on specific types of the nonhormonal IUD used (copper, Lippes loop, Dalkon Shield, Majzlin spring, and stainless steel); thus, the data for types were too sparse to pool.

The use of the LNG-IUS to protect from endometrial cancer is one of the most important issues regarding cancer risk and contraception (Hubacher \& Grimes 2002) as well as HRT (Riphagen 2000). However, studies on primary risk reduction in general populations are still lacking, although in 2008, at least three studies and two case reports for effective treatment of endometrial hyperplasia (including even atypical or complex histology) were published (Haimovich et al. 2008, Oerbo et al. 2008, Qi et al. 2008, Varma et al. 2008), in addition to a series of earlier reports (Vereide et al. 2003, 2005, Giannopoulos et al. 2004, Wildemeersch et al. 2007).

To our knowledge, only very few case reports, but no special study, raised doubts about the effectiveness of LNG-IUS for treatment of endometrial hyperplasia. However, even endometrial protection against tamoxifen-stimulated endometrial changes by using LNG-IUS was demonstrated in several studies (Gardner et al. 2000, Chan et al. 2007, Kesim et al. 2008). All in all, it can be concluded that LNG-IUS is a promising alternative to hysterectomy for the treatment of endometrial hyperplasia, although data are too sparse to recommend treatment of early endometrial cancer, and case reports are controversial (Parazzini et al. 1994, Sturgeon et al. 1997, Varila et al. 2001, Giannopoulos et al. 2004, Dhar et al. 2005, Kresowik et al. 2008).

\section{Mechanisms using nonhormonal and hormonal IUDs}

It can be expected that LNG-IUS used for contraception protects primarily from endometrial cancer as do nonhormonal IUDs, although the mechanism differs between these IUSs (Aikat \& Chadda 1980, Nilsson et al. 1982, Johannisson 1987, Castellsague et al. 1993, Raudaskoski et al. 1998, Phillips et al. 2003, Vereide et al. 2005, 2006). Regarding the possible mechanisms of protection, there are important differences between nonhormonal IUDs and the (until now only available) hormonal LNG-IUS: although local intrauterine changes are suggested to be the main effect for contraception with both systems within a few days after insertion, only local endometrial effects without relevant systemic side effects (e.g. no relevant copper absorption) are associated with nonhormonal IUDs (Beining et al. 2008). The mechanisms of nonhormonal IUDs are to develop local chronic inflammation leading to inhibition of nidation, and perhaps in addition also releasing mediators that have a toxic impact on sperm motility and sperm metabolism, although until now the detailed understanding has been a matter of intensive research with some questions remaining open.

In contrast, systemic effects cannot be excluded when using the LNG-IUS. Mean plasma levels of levonorgestrel can be assessed to be in the range of about $150-200 \mathrm{pg} / \mathrm{ml}(0.4-0.6 \mathrm{nmol} / \mathrm{l})$, whereas endometrial tissue levels more than tenfold higher are obtained (Riphagen 2000). Thus, side effects similar to those seen with orally or parenterally administered progestin-only preparations have been observed in the studies, but are very rare. For practical use, it seems important that the same contraindications are labeled for the use of LNG-IUS as with other progestin-only preparations, and have to be considered when attaining patients' informed consent.

However, the main effect of LNG-IUS is to decrease the local endometrial response to estrogen, as with the use of systemically administered progestins when added to estrogen therapy (Pike \& Spicer 2000, Riphagen 2000). During progestogen action, cell proliferation ceases despite continuous exposure to 
estrogen levels (as in the luteal phase). Progestogens protect from estrogen-induced hyperplasia and changes in proliferative status. They induce glandular epithelial secretory activity and decidual transformation of stromal fibroblasts; these terminally differentiated cells can no longer proliferate and are shed in withdrawal bleeding (if implantation does not occur), with strong differences dependent on the pharmacology of progestogens used (type, dosage, pharmacokinetics, etc; Pike \& Spicer 2000). This is suggested to be the main mechanism regarding endometrial effects of all progestin-only preparations. With longer use, there are atrophic changes combined with amenorrhea. In most cases, this occurs within 6-12 months of LNG-IUS insertion. However, if this can lead to primary protection from endometrial cancer, then clinical end point studies into LNG-IUS and endometrial protection are urgently needed.

\section{Declaration of interest}

The authors declare that there is no conflict of interest that could be perceived as prejudicing the impartiality of the review reported.

\section{Funding}

This review did not receive any specific grant from any funding agency in the public, commercial, or not-for-profit sector.

\section{References}

Aikat M \& Chadda U 1980 Long-term effects of copper intrauterine devices on cervical epithelium and endometrium. Indian Journal of Medical Research 71 879-883.

Beining RM, Dennis LK, Smith EM \& Dokras A 2008 Metaanalysis of intrauterine device use and risk of endometrial cancer. Annals of Epidemiology 18 492-499. (doi:10. 1016/j.annepidem.2007.11.011)

Beral V, Hannaford P \& Kay C 1988 Oral contraceptive use and malignancies of the genital tract: results from the Royal College of General Practitioners' Oral Contraception Study. Lancet 332 1331-1335. (doi:10.1016/ S0140-6736(88)90869-0)

Brinton LA \& Hoover RN 1993 Estrogen replacement therapy and endometrial cancer risk: unresolved issues. Obstetrics and Gynecology 81 265-271.

CASH (Cancer and Steroid Hormone) 1987 Study of the Centers for Disease Control and the National Institute of Child Health and Human Development. Combination oral contraceptive use and the risk of endometrial cancer. Journal of the American Medical Association 257 796-800. (doi:10.1001/jama.257.6.796)
Castellsague X, Thompson WD \& Dubrow R 1993 Intrauterine contraception and the risk of endometrial cancer. International Journal of Cancer 54 911-916. (doi:10. 1002/ijc.2910540607)

Chan SSC, Tam WH, Yeo W, Yu MMY, Ng DPS, Wong AWY, Kwan WH \& Yuen PM 2007 A randomised controlled trial of prophylactic levonorgestrel intrauterine system in tamoxifen-treated women. British Journal of Obstetrics and Gynaecology 114 1510-1515. (doi:10.1111/j.1471-0528.2007.01545.x)

Dhar KK, NeedhiRajan T, Koslowski M \& Woolas RP 2005 Is levonorgestrel intrauterine system effective for treatment of early endometrial cancer? Report of four cases and review of the literature. Gynecologic Oncology 97 924-927. (doi:10.1016/j.ygyno.2004.10.031)

Gardner FJE, Konje JC, Abrams KR, Browns LJR, Khanna S, Al-Azzawi F, Bell SC \& Taylor DJ 2000 Endometrial protection from tamoxifen-stimulated changes by a levonorgestrel-releasing intrauterine system: a randomised controlled trial. Lancet 356 1711-1717. (doi:10. 1016/S0140-6736(00)03204-9)

Giannopoulos T, Butler-Mauel S \& Tailor A 2004 Levonorgestrel-releasing intrauterine system (LNG-IUS) as a therapy for endometrial carcinoma. Gynecologic Oncology 95 762-764. (doi:10.1016/j.ygyno.2004.09.010)

Grimes DA \& Economy KE 1995 Primary prevention of gynecologic cancers. American Journal of Obstetrics and Gynecology 172 227-235. (doi:10.1016/00029378(95)90125-6)

Haimovich S, Checa MA, Mancebo G, Fuste P \& Carreras R 2008 Treatment of endometrial hyperplasia without atypia in peri- and postmenopausal women with a levonorgestrel intrauterine device. Menopause 15 1002-1007. (doi:10.1097/gme.0b013e3181659837)

Hannaford PC, Selvaraj S, Elliott AM, Angus V, Iversen L \& Lee AJ 2007 Cancer risk among users of oral contraceptives: cohort data from the Royal College of General Practitioner's Oral Contraception Study. BMJ 335651. (doi:10.1136/bmj.39289.649410.55)

Heinemann LAJ, Lewis MA, Kühl-Habich D, Braendle W, Moehner S \& Raff T 2003 Use of oral contraceptives and risk of cancer of the uterine corpus or ovary. Two case-control studies. Geburtshilfe und Frauenheilkunde 63 1018-1026. (doi:10.1055/s-2003-42732)

Henderson BE, Casagrande JT, Pike MC, Mack T, Rosario I \& Duke A 1983 The epidemiology of endometrial cancer in young women. British Journal of Cancer $\mathbf{4 7}$ 749-756.

Horwitz RI \& Feinstein AR 1979 Case-control study of oral contraceptive pills and endometrial cancer. Annals of Internal Medicine 91 226-227.

Hubacher D \& Grimes DA 2002 Noncontraceptive health benefits of intrauterine devices: a systematic review. Obstetrical and Gynecological Survey 57 120-128. (doi:10.1097/00006254-200202000-00024)

Hulka BS, Chambless LE, Kaufman DG, Fowler WC Jr \& Greenberg BG 1982 Protection against endometrial 
carcinoma by combination-product oral contraceptives. Journal of the American Medical Association 247 475-477. (doi:10.1001/jama.247.4.475)

Jick SS, Waler AM \& Jick H 1993 Oral contraceptives and endometrial cancer. Obstetrics and Gynecology 82 931-935.

Johannisson E 1987 Mechanism of action of intrauterine devices: biochemical changes. Contraception 36 11-22. (doi:10.1016/0010-7824(87)90058-8)

Kaufman DW, Shapiro S, Slone D, Rosenberg L, Miettinen OS, Stolley PD, Knapp RC, Leavitt T Jr, Watring WG, Roseshein NB et al. 1980 Decreased risk of endometrial cancer among oral contraceptive users. New England Journal of Medicine 303 1045-1047. (doi:10.1056/ NEJM198010303031807)

Kelsey JL, LiVolsi VA, Holford TR, Fischer DB, Mostow ED \& Schwartz PE 1982 A case-control study of cancer of the endometrium. American Journal of Epidemiology 116 333-342.

Kesim MD, Aydin Y, Atis A \& Mandiraci G 2008 Long-term effects of the levonorgestrel-releasing intrauterine system on serum lipids and the endometrium in breast-cancer patients taking tamoxifen. Climacteric 11 252-257. (doi:10.1080/13697130802163168)

Koumantaki Y, Tzonou A, Koumantakis E, Kaklamani E, Aravantinos D \& Trichopoulos D 1989 A case-control study of cancer of the endometrium in Athens. International Journal of Cancer 43 795-799. (doi:10.1002/ijc.2910430509)

Kresowik J, Ryan GL \& Van Voorhis BJ 2008 Progression of atypical endometrial hyperplasia to adenocarcinoma despite intrauterine progesterone treatment with the levonorgestrel-releasing intrauterine system. Obstetrics and Gynecology 111 547-549. (doi:10.1097/01.AOG. 0000300716.84819.c6)

LaVecchia C, Decarli A, Parazzini F, Gentile A, Liberati C \& Franceschi S 1986 Oral contraceptives and cancers of the breast and oft the female genital tract: interim results from a case-control study. British Journal of Cancer 54 311-317.

Levi F, La Vecchia C, Gulie C, Negri E, Monnier V, Franceschi S, Delaloye JF \& De Grandi P 1991 Oral contraceptives and the risk of endometrial cancer. Cancer Causes and Control 2 99-103. (doi:10.1007/ BF00053128)

Maxwell GL, Schildkraut JM, Calingaert B, Risinger JI, Dainty L, Marchbanks PA, Berchuck A, Barrett JC \& Rodriguez GC 2006 Progestin and estrogen potency of combination oral contraceptives and endometrial cancer risk (CASH-study). Gynecologic Oncology 103 535-540. (doi:10.1016/j.ygyno.2006.03.046)

Nilsson CH, Haukkamaa M, Vierola H, Luukainen T \& Arcangeli P 1982 Tissue concentrations of levonorgestrel in women using a levonorgestrel-releasing IUD. Clinical Endocrinology 17 529-536. (doi:10.1111/j.1365-2265. 1982.tb01625.x)

Oerbo A, Arnes M, Hancke C, Vereide AB, Pettersen I \& Larsen K 2008 Treatment results of endometrial hyperplasia after prospective $D$-score classification: a follow-up study comparing the effect of LNG-IUD and oral progestins versus observation only. Gynecologic Oncology 111 68-73. (doi:10.1016/j.ygyno.2008.06.014)

Parazzini F, LaVecchia C \& Moroni S 1994 Intrauterine device use and risk of endometrial cancer. British Journal of Cancer 70 672-673.

Pettersson B, Adami HO, Bergstrom R \& Johansson EDB 1986 Menstruation span - a time-limited risk factor for endometrial carcinoma. Acta Obstetricia et Gynecologica Scandinavica 65 247-255. (doi:10.3109/ 00016348609155179)

Phillips V, Graham CT, Manek S \& McCluggage WG 2003 The effects of the levonorgestrel intrauterine system (Mirena coil) on endometrial morphology. Journal of Clinical Pathology 56 305-307. (doi:10.1136/jcp.56.4.305)

Pike MC \& Spicer D 2000 Hormonal contraception and chemoprevention of female cancers. Endocrine-Related Cancer 7 73-83. (doi:10.1677/erc.0.0070073)

Qi X, Zhao W, Duan Y \& Li Y 2008 Successful pregnancy following insertion of a levonorgestrel-releasing intrauterine system in two patients with complex atypical endometrial hyperplasia. Gynecologic and Obstetric Investigation 65 266-268. (doi:10.1159/000113308)

Ramcharan S, Pellegrin FA, Ray R \& Hsu JP 1981 The Walnut Creek Contraceptive Drug Study: a prospective study of the side effects of oral contraceptives. In Volume III. An interim report: a comparison of disease occurance leading to hospitalization or death in users and nonusers of oral contraceptives. Bethesda, MD, USA: US Department of Health, Education, and Welfare.

Raudaskoski T, Knip M \& Laatikainen T 1998 Plasma insulin-like growth factor 1 and its binding proteins 1 and 3 during coninuous non-oral and oral combined hormone replacement therapy. Menopause 5 217-222. (doi:10. 1097/00042192-199805040-00006)

Riphagen FE 2000 Intrauterine application of progestins in hormone replacement therapy: a review. Climacteric 3 199-211. (doi:10.1080/13697130008500114)

Schlesselman JJ 1997 Risk of endometrial cancer in relation to use of combined oral contraceptives. A practitioner's guide to meta-analysis. Human Reproduction 12 1851-1863. (doi:10.1093/humrep/12.9.1851)

Shu XO, Brinton LA, Zheng W, Gao YT, Fan J \& Fraumeni JF 1991 A population-based case-control study of endometrial cancer in Shanghai, China. International Journal of Cancer 49 38-43. (doi:10.1002/ijc.2910490108)

Stanford JL, Brinton LA, Berman ML, Mortel R, Twiggs LB, Barrett RJ, Wilbanks GD \& Hoover RN 1993 Oral contraceptives and endometrial cancer: do other risk factors modify the association? International Journal of Cancer 54 243-248. (doi:10.1002/ijc.2910540214)

Sturgeon SR, Brinton LA, Berman MI, Mortel R, Twiggs LB, Barrett RJ, Wilbanks GD \& Lurain JR 1997 Intrauterine device use and endometrial cancer risk. International Journal of Epidemiology 26 496-500.

Tao MH, Xu WH, Zheng W, Zhang Z-F, Gao Y-T, Ruan ZX, Cheng JR, Gao J, Xiang YB \& Shu XO 2006 
Oral contraceptive and IUD use and endometrial cancer: a population-based case-control study in Shanghai, China. International Journal of Cancer 119 2142-2147. (doi:10. 1002/ijc.22081)

Trapido EJ 1983 A prospective cohort study of oral contraceptives and cancer of the endometrium. International Journal of Epidemiology 12 297-300. (doi:10.1093/ije/12.3.297)

Varila E, Wahlstrom T \& Rauramo I 2001 A 5-year follow-up study on the use of levonorgestrel intrauterine system in women receiving hormone replacement therapy. Fertility and Sterility 76 969-973. (doi:10.1016/ S0015-0282(01)02846-1)

Varma R, Soneja H, Bhatia K, Ganesan R, Rollason T, Clark TJ \& Gupta JK 2008 The effectiveness of a levonorgestrel-releasing intrauterine system (LNG-IUS) in the treatment of endometrial hyperplasia - a long-term follow-up study. European Journal of Obstetrics, Gynecology, and Reproductive Biology 139 169-175. (doi:10.1016/j.ejogrb.2008.02.022)

Vereide AB, Arnes M, Straume B, Maltau JM \& Oerbo A 2003 Nuclear morphometric changes and therapy monitoring in patients with endometrial hyperplasia: a study comparing effects of intrauterine levonorgestrel and systemic medroxyprogesterone. Gynecologic Oncology 91 526-533. (doi:10.1016/j.ygyno.2003.07.002)

Vereide AB, Kaino T, Sager G \& Oerbo A 2005 Bcl-2, BAX, and apoptosis in endometrial hyperplasia after high-dose gestagen therapy: a comparison of responses in patients treated with intrauterine levonorgestrel and systemic medroxyprogesterone. Gynecologic Oncology 97 740-750. (doi:10.1016/j.ygyno.2005.02.030)

Vereide AB, Kaino T, Sager G, Arnes M \& Oerbo A 2006 Effect of levornorgestrel IUD and oral medroxyprogesterone acetate on glandular and stromal progesterone receptors and estrogen receptors in human endometrial hyperplasia. Gynecologic Oncology 101 214-223. (doi:10.1016/j.ygyno.2005.10.030)

Vessey M \& Painter R 2006 Oral contraceptive use and cancer. Findings in a large cohort study, 1968-2004. British Journal of Cancer 95 385-389. (doi:10.1038/sj. bjc.6603260)

Weiderpass E, Adami H-O, Baron JA, Magnusson C, Lindgren A \& Perrson I 1999 Use of oral contraceptives and endometrial cancer (Sweden). Cancer Causes and Control 10 277-284. (doi:10.1023/A:1008945721786)

Weiss NS \& Sayvetz TA 1980 Incidence of endometrial cancer in relation to the use of oral contraceptives. New England Journal of Medicine 302 551-554. (doi:10.1056/ NEJM198003063021004)

WHO Study of Neoplasia and Sterord Contraceptives 1988 Endometrial cancer and combined oral contraceptives. International Journal of Epidemiology 17 263-269. (doi:10.1093/ije/17.2.263)

WHO Collaborative Study of Neoplasia and Steroid Contraceptives 1991a Hormonal content of combined oral contraceptives in relation to the reduced risk of endometrial carcinoma. International Journal of Cancer 49 870-874. (doi:10.1002/ijc. 2910490612)

WHO Collaborative Study of Neoplasia and Steroid Contraceptives $1991 b$ Depot-medroxyprogesterone acetate and risk of endometrial cancer. International Journal of Cancer 49 186-190.

Wildemeersch D, Janssens D, Pylyser K, De Wever N, Verbeeck G, Dhont M \& Tjalma W 2007 Management of patients with non-atypical and atypical endometrial hyperplasia with a levonorgestrel-releasing system: longterm follow-up. Maturitas 57 210-213. (doi:10.1016/j. maturitas.2006.12.004) 